\title{
Association between Hepatitis B Surface Antigen Seropositivity and Metabolic Syndrome
}

\section{Tae-Heum Chung*, Moon-Chan Kim, Chang-Sup Kim}

Department of Family Medicine, Ulsan University Hospital, University of Ulsan College of Medicine, Ulsan, Korea

Background: Infection with hepatitis B virus (HBV) may be a risk factor for cardiovascular disease. We investigated the relationship between HBV infection and metabolic syndrome.

Methods: We performed a cross-sectional study of 9,474 Korean men and women who were at least 20 years old and who underwent a routine health check-up at Ulsan University Hospital in Ulsan, South Korea between March 2008 and February 2009. The associations of hepatitis B surface antigen (HBsAg) seropositivity with the presence of metabolic syndrome and its components were investigated by logistic regression analysis. Data were analyzed separately for males and females.

Results: HBsAg seropositivity was significantly negatively associated with hypertriglyceridemia and metabolic syndrome in men (odds ratio [OR], 0.39; 95\% confidence interval [CI], 0.29 to $0.50 ; \mathrm{P}<0.001$ and $\mathrm{OR}, 0.75 ; 95 \% \mathrm{CI}, 0.57$ to $0.98, \mathrm{P}=$ 0.033). In women, HBsAg seropositivity was also significantly negatively associated with hypertriglyceridemia, but not with metabolic syndrome (OR, $0.40 ; 95 \% \mathrm{CI}, 0.17$ to $0.91 ; \mathrm{P}=0.029$ and $\mathrm{OR}, 0.80 ; 95 \% \mathrm{CI}, 0.38$ to $1.66, \mathrm{P}=0.545)$.

Conclusion: HBV infection was significantly negatively associated with hypertriglyceridemia and metabolic syndrome in men and hypertriglyceridemia in women.

Keywords: Hepatitis B; Metabolic Syndrome; Triglycerides

\section{INTRODUCTION}

Metabolic syndrome refers to a constellation of metabolic abnormalities that increase the risk of diabetes and cardiovascular disease, including central obesity, hypertriglyceridemia, low high density lipoprotein (HDL) cholesterol, hypertension, and hyperglycemia. ${ }^{1)}$ The prevalence of metabolic syndrome

Received: May 2, 2011, Accepted: February 21, 2014

${ }^{*}$ Corresponding Author: Tae-Heum Chung

Tel: +82-52-250-7220, Fax: +82-52-250-8330

E-mail: jeongth@uuh.ulsan.kr

Korean Journal of Family Medicine

Copyright (C) 2014 The Korean Academy of Family Medicine

(c) This is an open-access article distributed under the terms of the Creative Commons Attribution Non-Commercial License (http://creativecommons.org/licenses/by-nc/3.0) which permits unrestricted noncommercial use, distribution, and reproduction in any medium, provided the original work is properly cited. has remarkably increased in industrialized countries, including South Korea, due to increasing obesity levels. ${ }^{1)}$ The prevalence of metabolic syndrome was $23.6 \%$ in 1998 and $28.0 \%$ in 2001, according to the Korean National Health and Nutritional Examination Surveys (KNHANES). ${ }^{2)}$

Around the world, an estimated 350 million persons are chronically infected with the hepatitis B virus (HBV), resulting in 600,000 deaths annually from cirrhosis, liver failure, and hepatocellular carcinoma. ${ }^{3,4)}$ Infection with $\mathrm{HBV}$ is a significant public health problem in South Korea. Although the incidence of new infections declined in South Korea following the introduction of vaccination in 1983 and the implementation of programs to vaccinate school children in 1988 and neonates in 1995, the prevalence of infection with HBV remains high in persons born before 1983. The prevalence of hepatitis B surface antigen (HBsAg) is $0.4 \%$ in South Koreans born after 1988 and $4.1 \%$ in those born before 1983, according to a 2005 


\section{KNHANES. ${ }^{5)}$}

A large body of experimental and epidemiologic evidence suggests that infectious agents contribute to atherosclerosis, which ultimately leads to cardiovascular disease. ${ }^{6,7)}$ Furthermore, some researchers have reported that infectious agents such as Chlamydia pneumonia, Helicobacter pylori, cytomegalovirus and herpes simplex virus type 1 are significantly associated with metabolic syndrome. ${ }^{8,9)}$

A few studies have explored whether HBV is associated with atherosclerosis or cardiovascular disease, but most studies failed to show a significant association. ${ }^{10-13)}$ Since the liver plays an essential role in the development of metabolic syndrome ${ }^{1)}$ and $\mathrm{HBV}$ infection is detrimental to hepatocytes, investigation of the relationship between HBV infection and metabolic syndrome in areas with high prevalence rates of both would be a practical approach to elucidate the effect of $\mathrm{HBV}$ infection on cardiovascular disease.

Recently, three studies investigated the association between $\mathrm{HBV}$ infection and metabolic syndrome, with inconsistent results. Two studies reported a negative association between the two, ${ }^{14)}$ and one study found a positive association. ${ }^{15)}$ Moreover, the methodologies of these studies of Chinese ${ }^{14)}$ or Taiwanese subects ${ }^{15,16)}$ had several limitations such as insufficient adjustment for confounding factors, ${ }^{14,16)}$ the use of hepatitis B core antibody (anti-HBc) but not $\mathrm{HBsAg}$ as evidence for $\mathrm{HBV}$ infection, and study populations that consisted of a specific age group $(19.2 \pm 2.3$ years old freshmen). ${ }^{15)}$ In addition, these studies did not explore how gender differences affected the association between HBV infection and metabolic syndrome. ${ }^{14-16)}$ We therefore assessed whether HBsAg seropositivity as a sign of HBV infection is associated with metabolic syndrome after adjustment for varied confounding factors in Korean men and women using data obtained from routine health check-ups.

\section{METHODS}

\section{Participants and Procedures}

Data were obtained from 9,474 (i.e., 7,602 men and 1,872 women) subjects who were at least 20 years old and who underwent a routine health check-up at the Ulsan University Hospital Heath Promotion Center (UUH-HPC) in Ulsan,
South Korea, between March 2008 and February 2009. A total of 17,816 subjects were examined during this period, of whom 6,081 had missing values in their characteristics, 3,054 were taking medicine, and 405 had chronic diseases such as thyroid disease, lung disease, kidney disease, rheumatoid arthritis, psychiatric disorder, or malignancy. These 8,342 subjects were excluded from the study, but 491 men and women who were taking medicine for dyslipidemia, hypertension, or diabetes were included. 9,474 subjects were finally included in the analysis. Although the excluded subjects were more likely to be younger and have a slightly worse lifestyle, HBsAg seropositivity was comparable between the excluded and included subjects (data not shown). More than $90 \%$ of the subjects were employed by, or had family members who were employed by, manufacturing companies that paid for the health check-ups. Most subjects did not present with symptoms. The subjects' average family income was consistent with that of South Korea. The study protocol was approved by the institutional review board of UUH.

\section{Data Collection}

Subjects who visited UUH-HPC were asked to complete a questionnaire about lifestyle, medical history, and family income. Lifestyle data included alcohol intake, smoking, and exercise. Medical history data included current diseases and medication. Height, weight, waist circumference (WC), and blood pressure (BP) were measured by trained nurses, and blood tests for lipid profiles, fasting plasma glucose (FPG), alanine aminotransferase (ALT), and a serologic test for HBsAg were performed.

Body weight and height were measured in subjects wearing light indoor clothing without shoes, consistent with a standard protocol. Body mass index (BMI) was defined as body weight in kilograms divided by the square of the height in meters. WC was measured at the midpoint between the lowest ribs and the ileac crest. BP was measured by trained nurses using a mercury sphygmomanometer according to a standard protocol. ${ }^{17)}$ Subjects sat quietly for 5 minutes before BP was measured with the subject' $\mathrm{s}$ arm supported at the level of the heart. The cuff was deflated at a rate of $2 \mathrm{~mm} \mathrm{Hg}$ per heartbeat. Blood samples were drawn from the antecubital vein more than 12 hours after the last meal, and serum triglyceride, HDL cholesterol, FPG, and ALT were analyzed using an automated analyzer in the central laboratory of UUH. The HBsAg was measured via the microparticle enzyme 
immunoassay (Abbott, Chicago, IL, USA), as evidence of HBV infection. ALT abnormality was defined as serum ALT $>40 \mathrm{mg} /$ dL.

Alcohol intake was scored as $<1,1-2$, or $\geq 3$, according to the number of days per week of alcohol consumption. Smoking status was scored as 'never smoked,' 'former smoker,' and 'current smoker.' Physical exercise was scored as $<1,1-2$, or $\geq 3$, according to the number of days per week of exercise. Family income was scored as $<1,500,1,500-3,000$, or $>3,000$ US dollars per month. The average monthly income per household in Korea was 2,625 US dollars in 2008. ${ }^{18)}$ Educational status was scored as $\leq 9$ years (i.e., middle school graduates), 10 to 12 years (i.e., high school graduates), and $\geq 13$ years (i.e., college graduates).

\section{Definition of Metabolic Syndrome}

Consistent with 2001 criteria established by the National Cholesterol Education Program's Adult Treatment Panel III, ${ }^{1)}$ the American Diabetes Association for Hyperglycemia, ${ }^{19)}$ and the Korean guidelines for $\mathrm{WC},{ }^{20)}$ metabolic syndrome was defined as three or more of the following components: 1) central obesity (i.e., WC $\geq 90 \mathrm{~cm}$ in men or $\geq 85 \mathrm{~cm}$ in women; 2) hypertriglyceridemia (i.e., triglyceride $\geq 150 \mathrm{mg} / \mathrm{dL}$ or specific medication); 3) low HDL cholesterol (i.e., HDL cholesterol $<40 \mathrm{mg} / \mathrm{dL}$ in men and $<50 \mathrm{mg} / \mathrm{dL}$ in women or specific medication); 4) hypertension (i.e., $\mathrm{BP} \geq 130 \mathrm{~mm} \mathrm{Hg}$ systolic $\mathrm{BP}$ or $\geq 85 \mathrm{~mm} \mathrm{Hg}$ diastolic BP or specific medication); 5) hyperglycemia (i.e., FPG $\geq 100 \mathrm{mg} / \mathrm{dL}$ or specific medication or previously diagnosed type 2 diabetes).

\section{Statistical Analysis}

We analyzed the association between HBV infection and metabolic syndrome, using HBsAg seropositivity as an independent variable regardless of chronic hepatitis $\mathrm{B}$ or low activity $\mathrm{HBV}$ carrier and using metabolic syndrome and its five components as dependent variables. Data were analyzed separately for males and females. The characteristics of the study subjects in HBsAg seropositive and seronegative groups were compared using Student t-tests for continuous variables and chi-square tests for categorical variables. Triglyceride, HDL cholesterol, FPG, and ALT levels were log transformed because their distribution was skewed to the right of the normal distribution. The odds ratios of metabolic syndrome and its components were calculated using a logistic regression model. Age, BMI, ALT, alcohol intake, smoking, exercise, family income, and education level were included in the multivariate analysis. P-values of less than 0.05 were considered to indicate statistical significance. All statistical analyses were performed using Stata SE ver. 10.0 (Stata Co., College Station, TX, USA).

\section{RESULTS}

\section{Characteristics of Study Subjects with Regards to Sex and Hepatitis B Virus Infection}

The prevalence of HBV infection in men was $5.7 \%$. Triglyceride levels were significantly lower in $\mathrm{HBsAg}$-positive than in HBsAg-negative men $(4.59 \pm 0.48$ [SD] versus $4.75 \pm$ $0.52 \mathrm{mg} / \mathrm{dL}, \mathrm{P}<0.001)$ and HDL cholesterol levels were also significantly lower in $\mathrm{HBsAg}$-positive than in HBsAg-negative men $(3.81 \pm 0.26[\mathrm{SD}]$ versus $3.84 \pm 0.25 \mathrm{mg} / \mathrm{dL}, \mathrm{P}=0.039)$ (Table 1). ALT level was significantly higher in HBsAg-positive than in HBsAg-negative men $(3.35 \pm 0.53$ [SD] versus $3.15 \pm$ $0.45 \mathrm{mg} / \mathrm{dL}, \mathrm{P}<0.001)$. ALT abnormality was significantly higher in HBsAg-positive than in HBsAg-negative men (20.1\% versus $11.2 \%, \mathrm{P}<0.001)$. With regards to alcohol intake, HBsAgpositive men drank alcohol significantly fewer days per week than did HBsAg-negative men ( $\mathrm{P}<0.001)$. Age, BMI, WC, systolic BP, diastolic BP, and FPG were not significantly different in HBsAg-

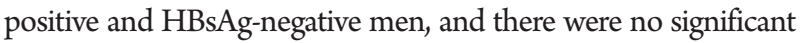
differences in their distributions between HBsAg-positive and $\mathrm{HBsAg-negative} \mathrm{men} \mathrm{with} \mathrm{regards} \mathrm{to} \mathrm{smoking,} \mathrm{exercise,} \mathrm{family}$ income, and education level.

In women, the prevalence of HBV infection was $4.5 \%$. Triglyceride levels were lower in HBsAg-positive than in HBsAg-negative women, but this difference was not statistically significant $(4.45 \pm 0.39[\mathrm{SD}]$ versus $4.50 \pm 0.50 \mathrm{mg} / \mathrm{dL}, \mathrm{P}=$ 0.328). ALT level was significantly higher in HBsAg-positive than in HBsAg-negative women $(3.11 \pm 0.56$ [SD] versus $2.81 \pm 0.43$ $\mathrm{mg} / \mathrm{dL}, \mathrm{P}<0.001]$. ALT abnormality was significantly higher in HBsAg-positive than in HBsAg-negative women (11.9\% versus $3.5 \%, \mathrm{P}<0.001)$. Age, BMI, WC, HDL cholesterol, systolic BP, diastolic BP, and FPG were not significantly different in HBsAgpositive and $\mathrm{HBs} A g$-negative women and there was no significant difference in distribution between HBsAg-positive and HBsAg- 
Table 1. Characteristics of study subjects with regards to sex and hepatitis B virus infection

\begin{tabular}{|c|c|c|c|c|c|c|}
\hline \multirow[b]{2}{*}{ Characteristic } & \multicolumn{3}{|c|}{$\operatorname{Men}(n=7,602)$} & \multicolumn{3}{|c|}{ Women $(\mathrm{n}=1,872)$} \\
\hline & $\begin{array}{l}\text { HBsAg (-) } \\
(\mathrm{n}=7,165)\end{array}$ & $\begin{array}{c}\text { HBsAg (+) } \\
(\mathrm{n}=437)\end{array}$ & P-value* & $\begin{array}{l}\text { HBsAg }(-) \\
(\mathrm{n}=1,788)\end{array}$ & $\begin{array}{c}\text { HBsAg (+) } \\
(\mathrm{n}=84)\end{array}$ & P-value* \\
\hline Age (y) & $50.0 \pm 6.0$ & $45.7 \pm 5.7$ & 0.818 & $47.0 \pm 9.9$ & $45.4 \pm 9.4$ & 0.150 \\
\hline Body mass index $\left(\mathrm{kg} / \mathrm{m}^{2}\right)$ & $23.8 \pm 2.6$ & $23.9 \pm 2.5$ & 0.158 & $22.9 \pm 3.0$ & $23.2 \pm 3.0$ & 0.376 \\
\hline Waist circumference $(\mathrm{cm})$ & $84.6 \pm 7.1$ & $85.1 \pm 7.0$ & 0.150 & $79.0 \pm 7.9$ & $79.5 \pm 7.7$ & 0.554 \\
\hline Triglyceride $(\mathrm{mg} / \mathrm{dL})^{\dagger}$ & $4.75 \pm 0.52$ & $4.59 \pm 0.48$ & $<0.001$ & $4.50 \pm 0.50$ & $4.45 \pm 0.39$ & 0.328 \\
\hline High density lipoprotein cholesterol $(\mathrm{mg} / \mathrm{dL})^{\dagger}$ & $3.84 \pm 0.25$ & $3.81 \pm 0.26$ & 0.039 & $3.97 \pm 0.24$ & $4.01 \pm 0.20$ & 0.201 \\
\hline Systolic blood pressure (mm Hg) & $122.3 \pm 10.7$ & $123.2 \pm 11.0$ & 0.241 & $116.5 \pm 12.7$ & $116.2 \pm 12.2$ & 0.857 \\
\hline Diastolic blood pressure (mm Hg) & $79.4 \pm 7.1$ & $79.8 \pm 7.2$ & 0.451 & $74.9 \pm 8.4$ & $74.9 \pm 7.9$ & 0.970 \\
\hline Fasting plasma glucose $(\mathrm{mg} / \mathrm{dL})^{\dagger}$ & $4.60 \pm 0.15$ & $4.60 \pm 0.15$ & 0.637 & $4.52 \pm 0.14$ & $4.52 \pm 0.12$ & 0.757 \\
\hline $\operatorname{ALT}(\mathrm{mg} / \mathrm{dL})^{\dagger}$ & $3.15 \pm 0.45$ & $3.35 \pm 0.53$ & $<0.001$ & $2.81 \pm 0.43$ & $3.11 \pm 0.56$ & $<0.001$ \\
\hline ALT abnormality (ALT > $40 \mathrm{mg} / \mathrm{dL}$ ) & 11.2 & 20.1 & $<0.001$ & 3.5 & 11.9 & $<0.001$ \\
\hline \multicolumn{7}{|l|}{ Alcohol intake (times/wk) ${ }^{\ddagger}$} \\
\hline$<1$ & 46.7 & 58.6 & $<0.001$ & 84.3 & 89.3 & 0.453 \\
\hline $1-2$ & 40.4 & 31.4 & & 13.5 & 9.5 & \\
\hline$\geq 3$ & 12.9 & 10.1 & & 2.2 & 1.2 & \\
\hline \multicolumn{7}{|l|}{ Smoking } \\
\hline Never & 20.1 & 22.4 & 0.432 & 96.3 & 97.6 & 0.819 \\
\hline Former & 42.5 & 42.6 & & 2.0 & 1.2 & \\
\hline Current & 37.4 & 35.0 & & 1.7 & 1.2 & \\
\hline \multicolumn{7}{|l|}{ Exercise (times/wk) ${ }^{\ddagger}$} \\
\hline$<1$ & 14.4 & 14.0 & 0.674 & 32.4 & 29.8 & 0.863 \\
\hline $1-2$ & 39.3 & 41.4 & & 32.3 & 34.5 & \\
\hline$\geq 3$ & 46.4 & 44.6 & & 35.3 & 35.7 & \\
\hline \multicolumn{7}{|l|}{ Income (US dollar/mo) } \\
\hline$<1,500$ & 37.1 & 38.0 & 0.928 & 40.0 & 36.9 & 0.538 \\
\hline $1500-3,000$ & 19.0 & 18.5 & & 19.0 & 23.8 & \\
\hline$>3,000$ & 43.9 & 43.5 & & 41.0 & 39.3 & \\
\hline \multicolumn{7}{|l|}{ Educational status $^{\ddagger}$} \\
\hline$<$ Middle school & 19.6 & 19.7 & 0.878 & 25.6 & 22.6 & 0.389 \\
\hline High school & 45.9 & 46.9 & & 40.1 & 47.6 & \\
\hline$\geq$ College & 34.6 & 33.4 & & 34.3 & 29.8 & \\
\hline
\end{tabular}

Values are presented as mean $\pm \mathrm{SD}$ or $\%$.

HBsAg: hepatitis B surface antigen, ALT: alanine aminotransferase.

*Based on t-tests for continuous variables and chi-square tests for categorical variables. ${ }^{\dagger}$ Log-transformed data. ${ }^{~}$ Percentages may not total 100 because of rounding. 
Table 2. Crude and adjusted ORs* and 95\% CIs for metabolic syndrome and its components according to the seropositivity of HBV infection in men

\begin{tabular}{|c|c|c|c|c|c|c|}
\hline Variable & $\begin{array}{c}\text { HBsAg }(-) \\
(\mathrm{n}=7,165)(\%)\end{array}$ & $\begin{array}{c}\operatorname{HBsAg}(+) \\
(\mathrm{n}=437)(\%)\end{array}$ & $\begin{array}{c}\text { Crude OR } \\
(95 \% \text { CI })\end{array}$ & P-value & $\begin{array}{l}\text { Adjusted OR } \\
\qquad(95 \% \mathrm{CI})^{\dagger}\end{array}$ & P-value \\
\hline \multicolumn{7}{|l|}{ Metabolic syndrome } \\
\hline Yes & 20.8 & 19.5 & $0.92(0.72-1.17)$ & 0.492 & $0.75(0.57-0.98)$ & 0.033 \\
\hline No & 79.2 & 80.6 & & & & \\
\hline \multicolumn{7}{|l|}{ Waist circumference $(\mathrm{cm})$} \\
\hline$\geq 90$ & 21.3 & 24.0 & $1.17(0.93-1.47)$ & 0.173 & $1.10(0.82-1.47)$ & 0.530 \\
\hline$<90$ & 78.3 & 76.0 & & & & \\
\hline \multicolumn{7}{|l|}{ Triglyceride (mg/dL) } \\
\hline$\geq 150$ & 29.4 & 17.4 & $0.51(0.39-0.65)$ & $<0.001$ & $0.39(0.29-0.50)$ & $<0.001$ \\
\hline$<150$ & 70.6 & 82.6 & & & & \\
\hline \multicolumn{7}{|c|}{ High density lipoprotein cholesterol (mg/dL) } \\
\hline$<40$ & 25.4 & 31.4 & $1.35(1.09-1.66)$ & 0.005 & $1.15(0.92-1.43)$ & 0.212 \\
\hline$\geq 40$ & 74.7 & 68.7 & & & & \\
\hline \multicolumn{7}{|l|}{ Blood pressure $(\mathrm{mm} \mathrm{Hg})^{\ddagger}$} \\
\hline$\geq 130 / 85$ & 31.8 & 33.0 & $1.05(0.86-1.29)$ & 0.614 & $1.02(0.82-1.26)$ & 0.880 \\
\hline$<130 / 85$ & 68.2 & 67.1 & & & & \\
\hline \multicolumn{7}{|c|}{ Fasting plasma glucose (mg/dL) } \\
\hline$\geq 100$ & 43.3 & 43.0 & $0.99(0.81-1.20)$ & 0.902 & $0.92(0.76-1.13)$ & 0.441 \\
\hline$<100$ & 56.7 & 56.9 & & & & \\
\hline
\end{tabular}

OR: odds ratios, CI: confidence intervals, HBV: hepatitis B virus, HBsAg: hepatitis B surface antigen.

*Determined via logistic regression. ${ }^{\dagger}$ Adjusted for age, body mass index, alanine aminotransferase, alcohol intake, smoking, exercise, family income, and educational status. ${ }^{\ddagger} \geq 130 \mathrm{~mm} \mathrm{Hg}$ systolic blood pressure or $\geq 85 \mathrm{~mm} \mathrm{Hg}$ diastolic blood pressure.

negative women with regards to in alcohol intake, smoking, exercise, family income, and education level.

\section{The Association between Hepatitis B Surface Antigen Positivity and Metabolic Syndrome}

Multiple logistic regression analysis of men, with metabolic syndrome as a dependent variable revealed a significant negative association between HBsAg positivity and metabolic syndrome (adjusted odds ratio [OR], 0.75; 95\% confidence interval [CI], 0.57 to $0.98 ; \mathrm{P}=0.033$ ) (Table 2). When five metabolic syndrome components were included as dependent variables, HBsAg positivity in men was significantly negatively associated with hypertriglyceridemia (adjusted OR, 0.39; 95\% CI, 0.29 to 0.50; $\mathrm{P}<0.001)$, but not significantly associated with central obesity, low HDL cholesterol, hypertension, or hyperglycemia.
In women, there was no significant association between $\mathrm{HBsAg}$ positivity and metabolic syndrome (adjusted OR, 0.80; 95\% CI, 0.38 to $1.66 ; \mathrm{P}=0.545$ ) (Table 3 ). HBsAg positivity in women was significantly negatively associated with hypertriglyceridemia (adjusted OR, 0.40; 95\% CI, 0.17 to 0.91; P = 0.029), but not significantly associated with central obesity, low HDL cholesterol, hypertension, or hyperglycemia.

\section{DISCUSSION}

Our cross-sectional study of Korean adults revealed that, in both sexes, $\mathrm{HBV}$ infection is significantly negatively associated with hypertriglyceridemia among the five components of metabolic syndrome (adjusted OR, 0.39; 95\% CI, 0.29 to 0.50; 
Table 3. Crude and adjusted ORs* and 95\% CIs for metabolic syndrome and its components according to the seropositivity of HBV infection in women

\begin{tabular}{|c|c|c|c|c|c|c|}
\hline Variable & $\begin{array}{c}\text { HBsAg }(-) \\
(\mathrm{n}=1,788)(\%)\end{array}$ & $\begin{array}{l}\text { HBsAg (+) } \\
(\mathrm{n}=84)(\%)\end{array}$ & $\begin{array}{c}\text { Crude OR } \\
(95 \% \mathrm{CI})\end{array}$ & P-value & $\begin{array}{l}\text { Adjusted OR } \\
\qquad(95 \% \mathrm{CI})^{\dagger}\end{array}$ & P-value \\
\hline \multicolumn{7}{|l|}{ Metabolic syndrome } \\
\hline Yes & 13.7 & 14.3 & $1.05(0.56-1.96)$ & 0.879 & $0.80(0.38-1.66)$ & 0.545 \\
\hline No & 86.3 & 85.7 & & & & \\
\hline \multicolumn{7}{|l|}{ Waist circumference $(\mathrm{cm})$} \\
\hline$\geq 85$ & 22.5 & 26.2 & $1.22(0.74-2.01)$ & 0.428 & $0.93(0.44-1.96)$ & 0.851 \\
\hline$<85$ & 77.5 & 73.8 & & & & \\
\hline \multicolumn{7}{|l|}{ Triglyceride (mg/dL) } \\
\hline$\geq 150$ & 15.0 & 8.3 & $0.52(0.24-1.13)$ & 0.098 & $0.40(0.17-0.91)$ & 0.029 \\
\hline$<150$ & 85.0 & 91.7 & & & & \\
\hline \multicolumn{7}{|c|}{ High density lipoprotein cholesterol (mg/dL) } \\
\hline$<50$ & 36.4 & 34.5 & $0.92(0.58-1.46)$ & 0.726 & $0.81(0.50-1.30)$ & 0.383 \\
\hline$\geq 50$ & 63.6 & 65.5 & & & & \\
\hline \multicolumn{7}{|l|}{ Blood pressure $(\mathrm{mm} \mathrm{Hg})^{\ddagger}$} \\
\hline$\geq 130 / 85$ & 18.8 & 17.9 & $0.94(0.53-1.66)$ & 0.830 & $0.88(0.47-1.62)$ & 0.674 \\
\hline$<130 / 85$ & 81.2 & 82.1 & & & & \\
\hline \multicolumn{7}{|c|}{ Fasting plasma glucose (mg/dL) } \\
\hline$\geq 100$ & 18.0 & 20.2 & $1.15(0.69-1.92)$ & 0.596 & $1.03(0.60-1.77)$ & 0.924 \\
\hline$<100$ & 82.0 & 79.8 & & & & \\
\hline
\end{tabular}

OR: odds ratios, CI: confidence intervals, HBV: hepatitis B virus, HBsAg: hepatitis B surface antigen.

*Determined via logistic regression. ${ }^{\dagger}$ Adjusted for age, body mass index, alanine aminotransferase, alcohol intake, smoking, exercise, family income, and educational status. ${ }^{\ddagger} \geq 130 \mathrm{~mm} \mathrm{Hg}$ systolic blood pressure or $\geq 85 \mathrm{~mm} \mathrm{Hg}$ diastolic blood pressure.

$\mathrm{P}<0.001$ in men; adjusted OR, 0.40; 95\% CI, 0.17 to $0.91 ; \mathrm{P}$ $=0.029$ in women), and significantly negatively associated with metabolic syndrome (adjusted OR, 0.75; 95\% CI, 0.57 to 0.98 ; P $=0.033$ ) in men but not in women (adjusted OR, 0.80; 95\% CI, 0.38 to $1.66 ; \mathrm{P}=0.545)$.

Previous studies have consistently shown a significant negative association between HBV infection and triglyceride levels. ${ }^{14,16,21,22)}$ After adjusting for gender and age, Jan et al. ${ }^{16)}$ found that hypertriglyceridemia (i.e., triglyceride $>150 \mathrm{mg}$ / $\mathrm{dL}$ ) was inversely associated with $\mathrm{HBV}$ infection in a Taiwanese population (adjusted OR, 0.65; 95\% CI, 0.60 to 0.69 ). Luo et al. ${ }^{14)}$ reported that $\mathrm{HBV}$ infection was inversely related to high concentration of serum triglycerides in a Chinese population (adjusted OR, 0.62; 95\% CI, 0.53 to 0.72 ).

Although ALT abnormality was more in HBsAg-positive than in HBsAg-negative subjects and positively associated with hypertriglyceridemia (data not shown), HBV infection was negatively associated with hypertriglyceridemia in our study. This suggests that HBV infection has an effect on the decrease in serum triglyceride levels, which was stronger than the positive relationship between ALT abnormality and hypertriglyceridemia. Kang et al. ${ }^{23)}$ reported that the hepatitis $\mathrm{B}$ virus $\mathrm{X}$ protein, which originated from the HBV genome, contributes to abnormal lipid metabolism by causing the accumulation of hepatic triglycerides and lowering serum triglyceride levels. However, it can be argued that the inverse association between $\mathrm{HBV}$ infection and hypertriglyceridemia results from selection bias, whereby subjects with known chronic liver disease are likely to adopt a healthier lifestyle (e.g., less alcohol consumption) and thereby have lower triglyceride levels because alcohol increases plasma triglyceride 
levels. HBsAg-positive men in the present study also drank less frequently than did HBsAg-negative men. Nevertheless, it does not seem that selection bias influenced the relationship between HBV infection and hypertriglyceridemia because we measured alcohol intake and adjusted for this variable in our analysis.

The association between HBV infection and HDL cholesterol remains controversial. Su et al. ${ }^{24)}$ reported that $\mathrm{HBV}$ infection was inversely associated with HDL cholesterol. On the other hand, two studies have shown that there is no significant association between $\mathrm{HBV}$ infection and HDL cholesterol, ${ }^{14,16)}$ consistent with the present findings. Few data are available on the relationship between $\mathrm{HBV}$ infection and central obesity and hypertension. Two studies have reported that central obesity is not associated with $\mathrm{HBV}$ infection, consistent with our findings. ${ }^{14,16)}$ One of two studies also found that hypertension was negatively associated with $\mathrm{HBV}$ infection, but this association may reflect potential confounding factors such as alcohol intake. ${ }^{16)}$ Previous studies have generated conflicting data about the relationship between HBV infection and diabetes. Although some studies showed a positive $^{25)}$ or negative ${ }^{26)}$ association, others found that the prevalence of diabetes among patients with $\mathrm{HBV}$ and uninfected controls was similar. ${ }^{27,28)}$

Three studies explored the direct association between HBV infection and metabolic syndrome. Consistent with the present findings, Jan et al. ${ }^{16)}$ and Luo et al. ${ }^{14)}$ showed that HBV infection is significantly negatively associated with metabolic syndrome and hypertriglyceridemia. These results suggest that the disturbance of lipid metabolism affected by HBV infection may play a fundamental role in the development of metabolic syndrome. Conversely, Yen et al. ${ }^{15)}$ reported a significant positive association between anti-HBc and metabolic syndrome but did not explore the relationship between $\mathrm{HBs} A g$ and metabolic syndrome.

Our study had some advantages. We were able to take age, BMI, alcohol intake, smoking, exercise, family income, education level, and ALT level into consideration and examine the effects of $\mathrm{HBV}$ infection independently of potential confounders in the analysis with results reported by sex. In addition, HBsAg rather than anti-HBc was used to demonstrate $\mathrm{HBV}$ infection because the interpretation of positive anti-HBc varies with the presence of HBsAg or anti-HBs. ${ }^{29)}$

The present study had several limitations. First, the population may not be representative of all Koreans because over $90 \%$ of the study subjects were employed by, or were related to persons employed by, world-class industrial companies that provided stable living conditions and a generous family income. However, 5.7\% of the male and $4.5 \%$ of the female study subjects had HBsAg, consistent with other epidemiological studies of the prevalence of HBsAg carriers in Korea. ${ }^{5)}$ The prevalence of metabolic syndrome in this study population was $20.7 \%$ in men and $13.7 \%$ in women, compatible with other epidemiological studies of the prevalence of metabolic syndrome in Korea. ${ }^{2)}$ Future investigations are needed to validate our results in a more representative population. Second, we used the frequency of drinking per week instead of the total alcohol consumption because there were many missing values regarding the amount of drinking per unit time and the kind of alcoholic beverage. As a result, adjustment for only the frequency of drinking might not be enough to control for the whole effect of alcohol intake on triglyceride levels and the development of metabolic syndrome, because HBsAg-positive subjects were likely to drink less per unit time than were HBsAg-negative subjects. Third, we were not able to measure the total energy consumption from physical activity because we investigated only the frequency of exercise per week. Hence, our adjustment for physical activity may have been insufficient. Lastly, the findings from our study were from cross-sectional data; therefore, we could not investigate causality.

This cross-sectional study of Korean adults showed that HBV infection is significantly negatively associated with metabolic syndrome in men, but not in women, even though HBV infection is negatively associated with hypertriglyceridemia in both men and women. These findings are incompatible with the fact that most previous reports over the past decade found no significant relationship between $\mathrm{HBV}$ infection and atherosclerosis or cardiovascular disease. $^{10-13)}$ The essential mechanisms behind this discrepancy need to be further explored. Moreover, a prospective study with a more representative population is warranted in order to validate our results.

\section{CONFLICT OF INTEREST}

No potential conflict of interest relevant to this article was reported. 


\section{REFERENCES}

1. Eckel RH. The metabolic syndrome. In: Fauci AS, Kasper DL, Longo DL, Braunwald E, Hauser SL, Jameson JL, editors. Harrison's principles of internal medicine. 17th ed. Seoul: McGraw-Hill Korea; 2008. p. 1509-14.

2. Lim S, Park KS, Lee HK, Cho SI; Korean National Health and Nutrition Examination Surveys. Changes in the characteristics of metabolic syndrome in Korea over the period 1998-2001 as determined by Korean National Health and Nutrition Examination Surveys. Diabetes Care 2005;28:1810-2.

3. Dienstag JL. Hepatitis B virus infection. N Engl J Med 2008; 359:1486-500.

4. Hui CK, Leung N, Yuen ST, Zhang HY, Leung KW, Lu L, et al. Natural history and disease progression in Chinese chronic hepatitis B patients in immune-tolerant phase. Hepatology 2007;46:395-401.

5. Jeong S, Yim HW, Bae SH, Lee WC. Changes of hepatitis B surface antigen seroprevalence in Korea, 1998-2005. Korean J Epidemiol 2008;30:119-27.

6. Ross R. Atherosclerosis: an inflammatory disease. N Engl J Med 1999;340:115-26.

7. Smieja M, Gnarpe J, Lonn E, Gnarpe H, Olsson G, Yi Q, et al. Multiple infections and subsequent cardiovascular events in the Heart Outcomes Prevention Evaluation (HOPE) Study. Circulation 2003;107:251-7.

8. Gunji T, Matsuhashi N, Sato H, Fujibayashi K, Okumura M, Sasabe N, et al. Helicobacter pylori infection is significantly associated with metabolic syndrome in the Japanese population. Am J Gastroenterol 2008;103:3005-10.

9. Nabipour I, Vahdat K, Jafari SM, Pazoki R, Sanjdideh Z. The association of metabolic syndrome and Chlamydia pneumoniae, Helicobacter pylori, cytomegalovirus, and herpes simplex virus type 1: the Persian Gulf Healthy Heart Study. Cardiovasc Diabetol 2006;5:25.

10. Ishizaka N, Ishizaka Y, Takahashi E, Toda Ei E, Hashimoto H, Ohno $\mathrm{M}$, et al. Increased prevalence of carotid atherosclerosis in hepatitis B virus carriers. Circulation 2002;105:1028-30.

11. Tong DY, Wang XH, Xu CF, Yang YZ, Xiong SD. Hepatitis $B$ virus infection and coronary atherosclerosis: results from a population with relatively high prevalence of hepatitis B virus. World J Gastroenterol 2005;11:1292-6.
12. Volzke H, Schwahn C, Wolff B, Mentel R, Robinson DM, Kleine V, et al. Hepatitis B and C virus infection and the risk of atherosclerosis in a general population. Atherosclerosis 2004;174:99-103.

13. Kiechl S, Egger G, Mayr M, Wiedermann CJ, Bonora E, Oberhollenzer F, et al. Chronic infections and the risk of carotid atherosclerosis: prospective results from a large population study. Circulation 2001;103:1064-70.

14. Luo B, Wang Y, Wang K. Association of metabolic syndrome and hepatitis B infection in a Chinese population. Clin Chim Acta 2007;380:238-40.

15. Yen SL, Chiu TY, Lin YC, Lee YC, Lee LT, Huang KC. Obesity and hepatitis B infection are associated with increased risk of metabolic syndrome in university freshmen. Int J Obes (Lond) 2008;32:474-80.

16. Jan CF, Chen CJ, Chiu YH, Chen LS, Wu HM, Huang CC, et al. A population-based study investigating the association between metabolic syndrome and hepatitis $\mathrm{B} / \mathrm{C}$ infection (Keelung Community-based Integrated Screening study No. 10). Int J Obes (Lond) 2006;30:794-9.

17. Frohlich ED. Recommendations for blood pressure determination by sphygmomanometry. Ann Intern Med 1988;109:612.

18. Statistics Korea. Korean Statistical Information Service. Household income and expenditure [Internet]. Daejeon: Statistics Korea [cited 2009 Sep 20]. Available from: http:// kosis.kr/eng/.

19. Genuth S, Alberti KG, Bennett P, Buse J, Defronzo R, Kahn R, et al. Follow-up report on the diagnosis of diabetes mellitus. Diabetes Care 2003;26:3160-7.

20. Park H. Cut-off values of waist circumference for abdominal obesity among Koreans. J Korean Med Assoc 2005;48:116572.

21. Iannello S, Cavaleri A, Milazzo P, Cantarella S, Belfiore F. Low fasting serum triglyceride level as a precocious marker of autoimmune disorders. MedGenMed 2003;5:20.

22. Dai CY, Chuang WL, Ho CK, Hsieh MY, Huang JF, Lee LP, et al. Associations between hepatitis $\mathrm{C}$ viremia and low serum triglyceride and cholesterol levels: a community-based study. J Hepatol 2008;49:9-16.

23. Kang SK, Chung TW, Lee JY, Lee YC, Morton RE, Kim CH. The hepatitis $\mathrm{B}$ virus $\mathrm{X}$ protein inhibits secretion of apolipoprotein $\mathrm{B}$ by enhancing the expression of $\mathrm{N}$-acetylglucosaminyltransferase 
III.J Biol Chem 2004;279:28106-12.

24. Su TC, Lee YT, Cheng TJ, Chien HP, Wang JD. Chronic hepatitis B virus infection and dyslipidemia. J Formos Med Assoc 2004;103:286-91.

25. Li-Ng M, Tropp S, Danoff A, Bini EJ. Association between chronic hepatitis B virus infection and diabetes among Asian Americans and Pacific Islanders. Dig Liver Dis 2007;39:54956.

26. Bedarida G, D’Agostino F, Bianchi M, Susani G, Sangalli F, Fattorini A, et al. Unexpected lower prevalence of HBsAg in diabetics than in controls (A study on 2,465 patients). Ric
Clin Lab 1982;12:409-15.

27. Onyekwere CA, Anomneze EE, Wali SS. Prevalence of serological markers of chronic hepatitis B virus infection in diabetics in the Lagos University Teaching Hospital, Lagos. Niger Postgrad Med J 2002;9:129-33.

28. Wang CS, Wang ST, Yao WJ, Chang TT, Chou P. Communitybased study of hepatitis $\mathrm{C}$ virus infection and type 2 diabetes: an association affected by age and hepatitis severity status. Am J Epidemiol 2003; 158:1154-60.

29. Wilkins T, Zimmerman D, Schade RR. Hepatitis B: diagnosis and treatment. Am Fam Physician 2010;81:965-72. 